\title{
Surface Modification of Engineering Plastics through Swelling in Supercritical Carbon Dioxide
}

\author{
By Toshimi TAKAJO, ${ }^{1,2}$ Atsushi TAKAHARA, ${ }^{1, *}$ and Takefumi KICHIKAWA ${ }^{2}$
}

In order to improve the tribological characteristics of polymer materials, the authors tried to impregnate the surface of engineering plastics with the lubricating oil by using supercritical carbon dioxide. The oil impregnation ratio on crystalline polymer was influenced by both the glass transition temperature $\left(T_{\mathrm{g}}\right)$ and the degree of crystallinity. In case of using the polymer possessing lower $T_{\mathrm{g}}$ with large difference between the $T_{\mathrm{g}}$ and treatment temperature, the higher impregnation ratio was obtained, and the crystallite in crystalline polymer prevented the impregnation of lubricating oil. The results of polarized optical microscopic observations and FT-IR spectroscopy studies indicated that the lubricating oil was preferentially impregnated to the amorphous region in crystalline polymer, and the high-concentration layer of lubricating oil having the thickness of $c a .30 \mu \mathrm{m}$ was formed at the vicinity of surface area. The result obtained in this study, which reports the preferential lubricating oil impregnation to the surface of crystalline polymer under supercritical carbon dioxide, suggests that the tribological characteristics of crystalline polymer would be improved by applying this oil impregnation method without sacrificing the bulk mechanical strength.

KEY WORDS: Supercritical Carbon Dioxide / Oil Impregnation / Engineering Plastic / Tribology / Crystallinity /

Many studies carried out by utilizing supercritical fluid have been recently reported, and the representative examples of the studies are as follows: researches for the polymerization reaction in supercritical fluid, the supercritical extractionseparation technique, the supercritical fluid cleaning technology for precision parts, the coating technique using supercritical fluid on the surface of fine powder and on the inner wall surface of an optical cable, and the supercritical dyeing technique.

Now the substances of water, carbon dioxide and ethanol in the supercritical states are already industrially used. In the case of carbon dioxide, many studies ${ }^{1-7}$ for its application have been reported because carbon dioxide has the moderate critical conditions (the critical temperature $=304.2 \mathrm{~K}$, the critical pressure $=7.37 \mathrm{MPa}$ ) and is non-flammable, non-toxic and relatively inexpensive.

Polymer materials are widely used as an engineering material for parts used in various fields. For rolling bearings, which are important mechanical elements, the cages manufactured from polymer materials are used to arrange rolling elements such as balls equally and to prevent the metal-tometal contact. The cages are usually made from engineering plastics, and the resistance against lubricating oil is required as the fundamental property of material used for the bearing cage.

Recently, it has become more important to reduce the friction between the rolling elements and the cage due to the demand for higher fuel efficiency of automobiles. Application of oil-impregnated polymer to the cage material is one of the most appropriate ways for improving its frictional property. ${ }^{8}$ As traditional oil impregnation method for an oil-resistant polymer, there is a way of processing a polymer product in lubricating oil at high temperature over long periods of time to impregnate the product with lubricating oil. According to such the method, however, it is unavoidable that the deterioration of polymer is accelerated. Thus there was not optimum method available to impregnate polymer material with lubrication oil so far.

In this study, the oil impregnation experiments for representative crystalline and non-crystalline polymers using supercritical fluid were carried out for the purpose of developing a new technique to impregnate engineering plastics with lubricating oil. The influence of condition on the oil impregnation ratio and the oil dispersion state were investigated, furthermore, the oil impregnation mechanism under the existence of supercritical carbon dioxide was also discussed.

\section{EXPERIMENTAL}

\section{Polymers and Lubricating Oils}

In order to discuss the relationship between physicochemical properties of polymers and the oil impregnation behavior, various crystalline and non-crystalline polymers, which are shown in Table $\mathrm{I}^{9-13}$ and II, were used in this study. For crystalline polymers and non-crystalline polycarbonate (PC), extrusion-molded pieces manufactured by Nippon Polypenco Co., Ltd. were used. For amorphous polymethylmethacrylate (PMMA), commercially produced plates were used. The pieces machined into the shapes of circular discs with outside diameters of $35 \mathrm{~mm}$ and thicknesses of $3 \mathrm{~mm}$ were used as specimens. As lubricating oils, hydrocarbon synthetic oil, esterbased synthetic oil and ether synthetic oil, which are shown in Table III, ${ }^{14}$ were used in this study.

\footnotetext{
${ }^{1}$ Institute for Materials Chemistry and Engineering, Kyusyu University, 744 Motooka, Nishi-ku Fukuoka 819-0395, Japan

${ }^{2}$ Materials Technology Development Department, NSK Ltd, 1-5-50, Kugenuma Shinmei, Fujisawa 251-8501, Japan

*To whom correspondence should be addressed (Tel: +81-92-802-2517, Fax: +81-92-802-2518, E-mail: takahara@cstf.kyusyu-u.ac.jp).
} 
Table I. Chemical structures and thermal characteristics of crystalline polymers

\begin{tabular}{|c|c|c|c|c|c|}
\hline Polymer material & Abbreviation & Structural formula & $T_{\mathrm{g}} / \mathrm{K}$ & $\mathrm{Tm} / \mathrm{K}$ & $\begin{array}{c}\Delta \mathrm{H}_{\mathrm{f}}^{0} / \\
\mathrm{kJ} \mathrm{mol}^{-1}\end{array}$ \\
\hline $\begin{array}{l}\text { Ultra high molecular } \\
\text { weight polyethylene }\end{array}$ & UHMWPE & & 153 & 403 & 8.22 \\
\hline Polyoxymethylene & POM & & 217 & 448 & 9.79 \\
\hline $\begin{array}{l}\text { Polyvinylidene } \\
\text { fluoride }\end{array}$ & PVDF & & 238 & $\begin{array}{c}441 \text { to } \\
453\end{array}$ & 9.12 \\
\hline Polyamide 6 & PA6 & $\mathrm{O}=\frac{\mathrm{n}}{\mathrm{n}}$ & 323 & $\begin{array}{c}488 \text { to } \\
498\end{array}$ & 25.6 \\
\hline Polyamide 6,6 & PA6,6 & $\begin{array}{l}\mathrm{H} \\
\mathrm{HO} \\
\mathrm{N}-\left(\mathrm{CH}_{2}\right)_{6}-\mathrm{N}-\mathrm{N}-\mathrm{C}-\left(\mathrm{CH}_{2}\right)_{4}-{ }^{-}\end{array}$ & 339 & $\begin{array}{c}526 \text { to } \\
536\end{array}$ & 67.8 \\
\hline $\begin{array}{c}\text { Polyphenylene } \\
\text { Sulfide }\end{array}$ & PPS & & 363 & 558 & 15.8 \\
\hline Polyetheretherketone & PEEK & & 416 & 607 & - \\
\hline
\end{tabular}

Table II. Chemical structures and glass transition temperatures of non-crystalline polymers

\begin{tabular}{|c|c|c|c|}
\hline $\begin{array}{l}\text { Polymer } \\
\text { material }\end{array}$ & Abbreviation & Structural formula & $T_{\mathrm{g}} / \mathrm{K}$ \\
\hline $\begin{array}{l}\text { Polymethyl } \\
\text { methacrylate }\end{array}$ & PMMA & $\begin{array}{c}\mathrm{CH}_{3} \\
-\left(\mathrm{CH}_{2}-\mathrm{C}\right)_{\mathrm{n}}- \\
\mathrm{O}=\mathrm{C}-\mathrm{O}-\mathrm{CH}\end{array}$ & 378 \\
\hline Polycarbonate & PC & $\mathrm{CH}_{3}$ & $\begin{array}{c}413 \\
\text { to } 422\end{array}$ \\
\hline
\end{tabular}

\section{Equipment for Supercritical Carbon Dioxide Treatment} and Treatment Conditions

The equipment for the oil impregnation experiments in supercritical carbon dioxide is shown in Figure 1. The equipment used in this study is manufactured by Taiatsu Techno. Co., Ltd. The maximum allowable pressure is $29.5 \mathrm{MPa}$, the maximum allowable temperature is $523 \mathrm{~K}$, and the capacity of our high-pressure chamber is $1.0 \times 10^{-3} \mathrm{~m}^{3}$. The amount of lubricating oil for our oil impregnation experiments is $2.5 \times 10^{-5} \mathrm{~m}^{3}$. On the basis of assumed solubility of organic substance in supercritical carbon dioxide under our experimental condition, ${ }^{15,16}$ it was considered that this amount of $2.5 \times 10^{-5} \mathrm{~m}^{3}$ to the capacity of our chamber is sufficient for the purpose of maintaining a saturated concentration of lubricating oil.

Table III. Chemical structures, solubility parameters and molecular weights of lubricating oils

\begin{tabular}{|c|c|c|c|c|}
\hline Lubricating oil & $\begin{array}{l}\text { Abbre } \\
\text { viation }\end{array}$ & Structural formula & $\begin{array}{l}\text { Solubility } \\
\text { parameter, } \delta \\
\left(\mathrm{J} / \mathrm{cm}^{3}\right)^{1 / 2}\end{array}$ & $\begin{array}{c}\text { Molecular } \\
\text { weight }\end{array}$ \\
\hline $\begin{array}{l}\text { Polyalpha olefin } \\
\text { (Exxon-Mobile) }\end{array}$ & PAO & $\left(\begin{array}{r}\mathrm{CH}_{2}-\mathrm{CH} \\
1 \\
\mathrm{CH}_{3}\end{array}\right) \mathrm{n} \quad \mathrm{n}=33$ & 15.9 & 1386 \\
\hline $\begin{array}{l}\text { Alkyl diphenyl ether } \\
\text { (Matumura Oil research } \\
\text { Corp) }\end{array}$ & $A D E$ & $-\left(\mathrm{C}_{13} \mathrm{H}_{27}\right)_{\mathrm{n}}$ & 16.2 & 443 \\
\hline $\begin{array}{l}\text { Dioctyl sebacate } \\
\text { (Reagent, Wako Pure } \\
\text { Chemical Industries Ltd.) }\end{array}$ & DOS & $\begin{array}{cccc}\mathrm{CH}_{3}-\left(\mathrm{CH}_{2}\right)_{3}-\mathrm{CH}-\mathrm{CH}_{2}-\mathrm{O}-\mathrm{C}-\left(\mathrm{CH}_{2}\right)_{8}-\mathrm{C}-\mathrm{O}-\mathrm{CH}_{2}-\mathrm{CH}-\left(\mathrm{CH}_{2}\right)_{3}-\mathrm{CH}_{3} \\
\mathrm{C}_{2} \mathrm{H}_{5} & \text { O } & \text { O } & \text { I } \\
& & & \mathrm{C}_{2} \mathrm{H}_{5} \\
\end{array}$ & 17.3 & 426.8 \\
\hline $\begin{array}{c}\text { Polyolester } \\
\text { (NOF Corporation) }\end{array}$ & POE & 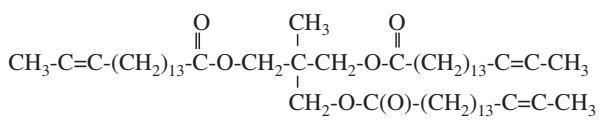 & 17.9 & 864 \\
\hline $\begin{array}{l}\text { Dioctyl adipate } \\
\text { (Daihachi Chemical } \\
\text { Industry Co., Ltd.) }\end{array}$ & DOA & $\begin{array}{rrrr}\mathrm{CH}_{3}-\left(\mathrm{CH}_{2}\right)_{3}-\mathrm{CH}-\mathrm{CH}_{2}-\mathrm{O}-\mathrm{C}-\left(\mathrm{CH}_{2}\right)_{4}-\mathrm{C}-\mathrm{O}-\mathrm{CH}_{2}-\mathrm{CH}-\left(\mathrm{CH}_{2}\right)_{3}-\mathrm{CH}_{3} \\
\mathrm{C}_{2} \mathrm{H}_{5} & \mathrm{O} & \mathrm{O} & \mathrm{C}_{2} \mathrm{H}_{5}\end{array}$ & 18.3 & 370 \\
\hline
\end{tabular}




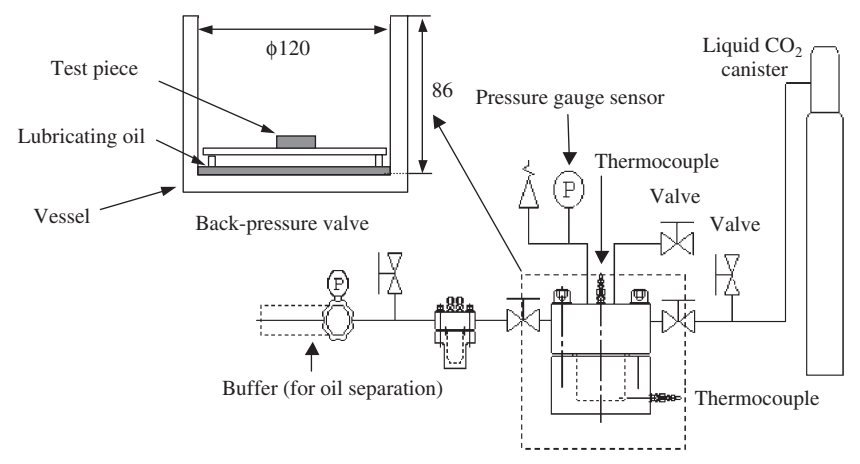

Figure 1. Schematic illustration of supercritical carbon dioxide treatment equipment.

The treatment procedure is as follows: First the weight of well-dried specimen is measured and then the specimen is placed with lubricating oil into the high-pressure chamber. The supercritical carbon dioxide treatment is carried out after the completion of substitution of carbon dioxide for air in the chamber, and the treatment is conducted at a specific temperature, time and pressure. After the specific time, the temperature is lowered to $303 \mathrm{~K}$ and, the pressure is gradually reduced. Here, the specific time means the time of period for which the equipment will be maintained under a constant condition after the temperature reached to the specific value. After the pressure was reduced to an atmospheric pressure level, the specimen is taken out, and then it must be placed into a vacuum desiccator for $5 \mathrm{~d}$ to remove residual carbon dioxide. Then the specimen weight is measured again, and using the weight after the treatment and the dried initial weight, the weight-increasing rate is calculated. Thus the impregnation ratio in this study is defined as the weight-increasing rate calculated using the specimen weights before and after the treatment. The representative treatment pattern is shown in Figure 2.
Generally, for supercritical carbon dioxide treatment, if pressure is rapidly reduced, microbubbles are formed in the polymer. ${ }^{17-20}$ In order to prevent the formations of such microbubbles, the specimen is usually taken out after the completion of the gradual cooling and pressure reduction. In this study, nevertheless, in order to elucidate the influence of cooling and pressure reduction process on the oil impregnation ratio, the oil impregnation experiment in which the rapid cooling and pressure reduction process was adopted, was also carried out.

\section{Determination of Degree of Crystallinity in Crystalline Polymer}

In order to determine the degree of crystallinity in crystalline polymer, the samples $(20 \mathrm{mg}$ each) were taken from the center and the edge of the specimen, and differential scanning calorimetry (DSC) measurement was conducted on each sample by using a Seiko Instruments Inc. DSC6220 under nitrogen. The sweep rate of temperature was $10 \mathrm{~K} / \mathrm{min}$, and the temperature range was $303 \mathrm{~K}$ through $573 \mathrm{~K}$. The degree of crystallinity is determined by quantifying the heat associated with melting of the polymer. That is, the degree of crystallinity is obtained by normalizing the observed apparent heat of fusion to that of a $100 \%$ crystalline sample of the same polymer. ${ }^{21}$ Here, the literature values are used for the heat of fusion values of $100 \%$ crystalline polymers.

\section{Microscopic Observation}

Thin film sections with the thickness of $5 \mu \mathrm{m}$ were prepared by using a microtome (Leica, RM2265). The microscopic images of film specimens were observed with a polarization optical microscope (Nikon, OPTIPHOT-POL) under the crossed Nicol condition. The analyses of oil dispersion states in the depth directions of specimens were carried out by a FT-IR microscope system ${ }^{22}$ (Thermo Electron, Nicolet Continuum XL FT-IR imaging system).

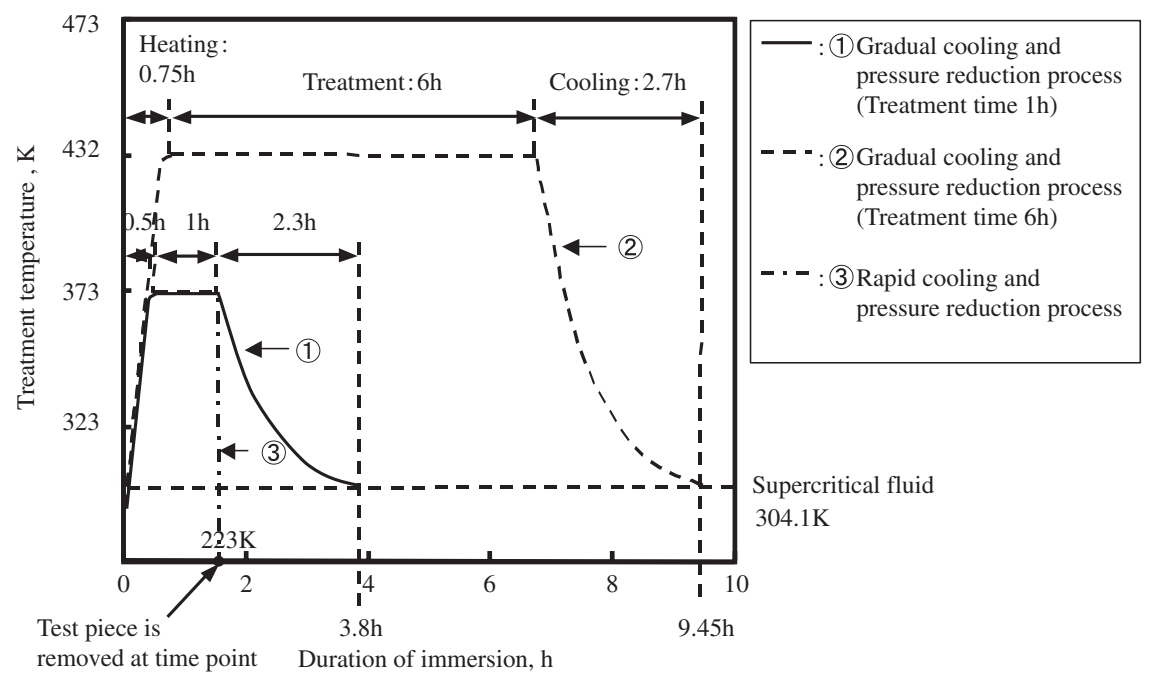

Figure 2. Treatment pattern on supercritical carbon dioxide treatment experiment. 


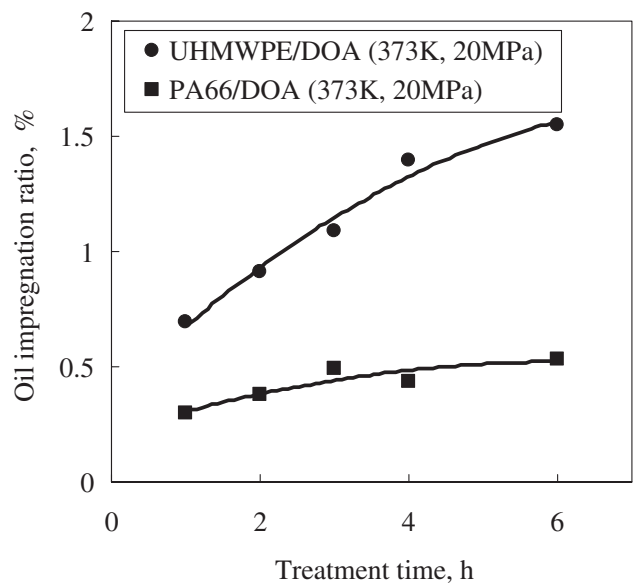

Figure 3. Time dependences of oil impregnation ratio for indicated samples.

\section{RESULTS AND DISCUSSION}

\section{Influence of Treatment Conditions on Impregnation Ratio}

In order to elucidate the influence of treatment conditions on the impregnation ratio, we treated ultra high molecular weight polyethylene (UHMWPE) and polyamide 6,6 (PA66) with dioctyl adipate (DOA) and alkyl diphenyl ether (ADE) lubricating oils in supercritical carbon dioxide by changing the individual conditions of temperature, pressure and time independently.

The time dependences of impregnation ratios are shown in Figure 3. This result shows the impregnation ratio increases with increasing the treatment time for both UHMWPE/DOA and PA66/DOA, and also qualitatively suggests the increasing ratio of oil impregnation depends on the kind of polymer, which is subjected to the treatment.

Figure 4 shows the variation of impregnation ratios with treatment temperature and pressure. From this result, it was found that the influence of temperature on the oil impregnation was significant for both cases of UHMWPE/DOA and PA66/ DOA. That is, although the higher pressure resulted in the higher oil impregnation, the pressure dependence of impregnation ratio was not so significant as the temperature dependence for both cases. In addition, in case of using different lubricating oils, similar results were obtained for the oil impregnation experiments in supercritical carbon dioxide for UHMWPE and PA66.

Relation between Impregnation Ratio and Physicochemical Properties of Crystalline Polymer and Lubricating Oil

Crystalline polymers and lubricating oils used for our oil impregnation experiments are summarized in Table I and Table III, respectively. The supercritical carbon dioxide treatments were carried out for $1 \mathrm{~h}$ at $373 \mathrm{~K}$ under the pressure of $20 \mathrm{MPa}$.

The data of impregnation ratios were represented as a contour graph as shown in Figure 5. In this figure, the horizontal axis indicates the glass transition temperature $\left(T_{\mathrm{g}}\right)$

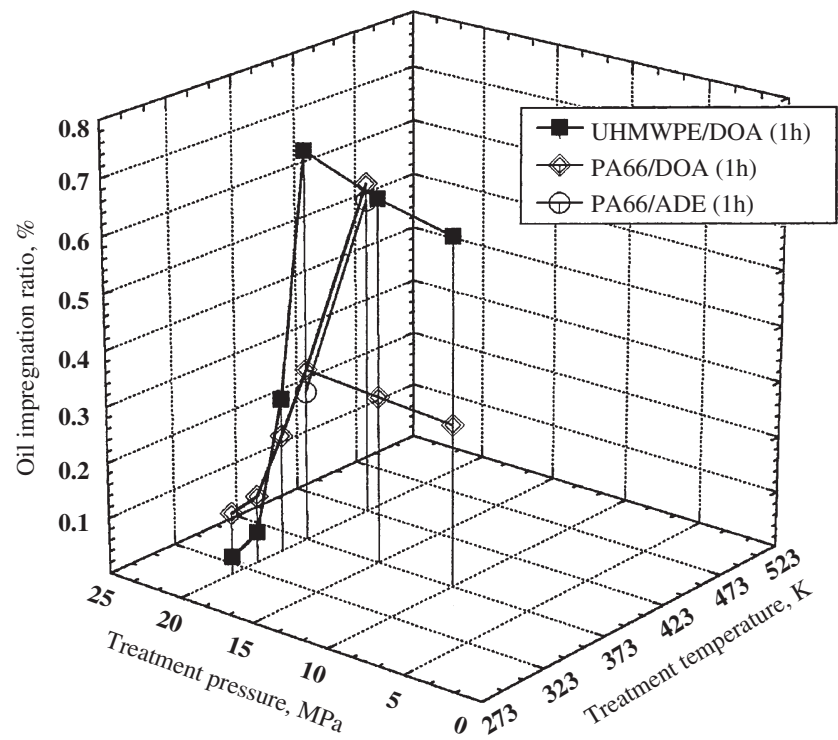

Figure 4. Temperature and pressure dependences of impregnation ratio for indicated samples.

of polymer, while vertical axis indicates the solubility parameter (SP) value of lubricating oil. This contour graph qualitatively reveals that in case of using the polymer having lower $T_{\mathrm{g}}$ and the lubricating oil with lower SP value, the higher value of impregnation ratio is obtained.

Exceptionally the impregnation ratio of polyoxymethylene (POM) having $T_{\mathrm{g}}$ of $217 \mathrm{~K}$ (second-lowest $T_{\mathrm{g}}$ value in the polymers used in this study) was relatively low as shown in Figure 5. This should be attributed to the highest degree of crystallinity of POM among those of crystalline polymers used in this study.

Besides, as shown in Figure 5, among three kinds of esterbased lubricating oils of dioctyl sebacate (DOS), DOA and polyolester (POE), the impregnation ratio in case of using POE was relatively low in comparison to the cases of using DOS and DOA, i.e., the impregnation ratio values of DOS, DOA and POE to UHMWPE were $0.7 \%, 0.7 \%$ and $0.35 \%$, respectively. This would be considered to be due to the higher molecular weight of POE than those of DOS and DOA.

\section{Impregnation Ratio of Lubricating Oil to Amorphous Region in Crystalline Polymer}

The relationships between the impregnation ratios of lubricating oil to amorphous regions and $T_{\mathrm{g}} \mathrm{s}$ of crystalline polymers (except polyetheretherketone), which are shown in Table IV, and non-crystalline polymers of PMMA and PC are shown in Figure 6. All the oil impregnation experiments were performed for $1 \mathrm{~h}$, at temperature of $373 \mathrm{~K}$ (above the $T_{\mathrm{g}} \mathrm{s}$ of all crystalline polymers) under the pressure of $20 \mathrm{MPa}$. Figure 6 evidently shows the crystalline polymer having lower $T_{\mathrm{g}}$ with larger difference between the $T_{\mathrm{g}}$ and treatment temperature, the higher impregnation ratio to the amorphous parts can be obtained when the treatments are conducted using identical oil under the same conditions. Naturally, the molecular 


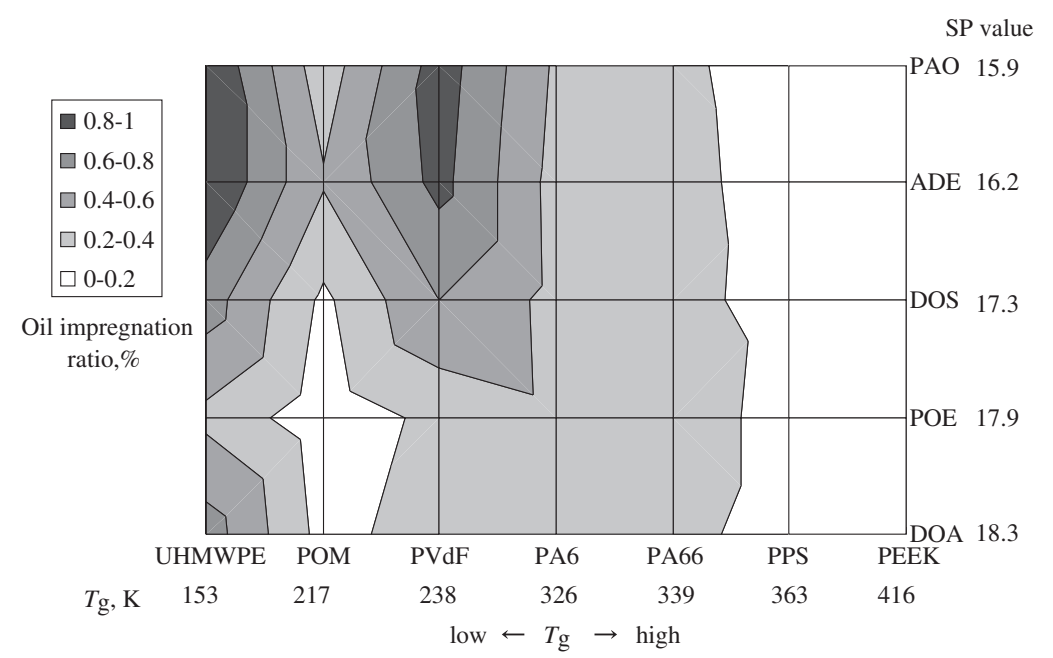

Figure 5. Contour graph of oil impregnation ratio, glass transition temperature $\left(T_{\mathrm{g}}\right)$ of polymers and solubility parameter (SP) value of lubricating oil. Here all data were obtained from the oil impregnation experiments that were conducted in supercritical carbon dioxide for $1 \mathrm{~h}$ at $373 \mathrm{~K}$ under the pressure of $20 \mathrm{MPa}$.

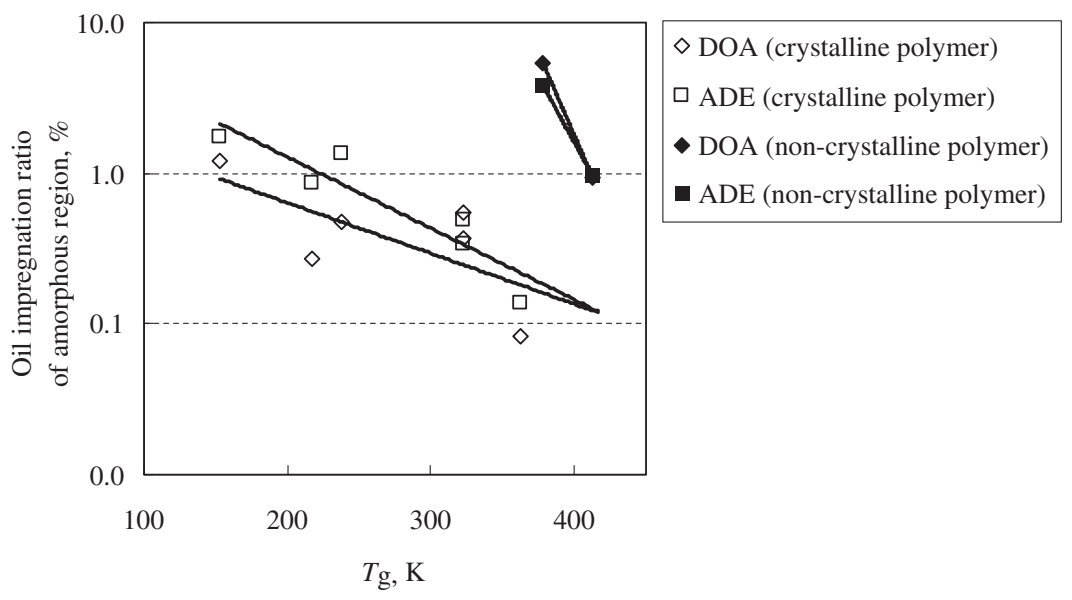

Figure 6. Relationships between impregnation ratios on amorphous regions and $T_{\mathrm{g}} \mathrm{s}$ of crystalline and non-crystalline polymers.

Table IV. Degree of crystallinity of crystalline polymers calculated by using the DSC data

\begin{tabular}{ccccccc}
\hline $\begin{array}{c}\text { Crystalline } \\
\text { polymers }\end{array}$ & UHMWPE & POM & PVDF & PA6 & PA6,6 & PPS \\
\hline $\begin{array}{c}\text { Degree of } \\
\text { crystallinity, } \%\end{array}$ & 41.9 & 51.6 & 36.7 & 32.9 & 19.7 & 28.4 \\
\hline
\end{tabular}

mobility of crystalline polymer having lower $T_{\mathrm{g}}$ must be enhanced higher than that of the polymer having higher $T_{\mathrm{g}}$, and thereby the polymer having lower $T_{\mathrm{g}}$ can show greater swelling in supercritical fluid than the polymer with higher $T_{\mathrm{g}}$. Therefore, higher impregnation ratio to the amorphous parts could be obtained in case of using the polymer possessing lower $T_{\mathrm{g}}$.

Further, a comparison of the impregnation ratios between crystalline and non-crystalline polymers shown in Figure 6 apparently shows that the lubricating oil can be impregnated to the intermolecular space in the amorphous state preferentially under the existence of supercritical carbon dioxide.

\section{Analysis of Dispersion State of Lubricating Oil Impreg- nated in Polymer}

Observation by Polarization Optical Microscope. Two specimens of crystalline-UHMWPE and non-crystalline-PC impregnated with DOA and ADE, respectively, were prepared and then their thin films were prepared by using a microtome. The microscopic images of film specimens were observed with a polarization microscope. The results are summarized in Figure 7.

As shown in these images, although the formation of highly ordered structure of crystallite, i.e., spherulites was not recognized in UHMWPE/DOA in spite of having the high degree of crystallinity, phase structures considered to be the crystalline granules were observed. On the other hand, noncrystalline PC/ADE showed only a uniform phase, unlike the observation result for UHMWPE/DOA.

\section{Evaluation of Dispersion State of Lubricating Oil Impreg- nated in Polymer by FT-IR Spectroscopy}

In order to clarify the dispersion state of lubricating oil in 


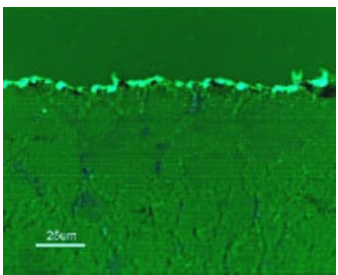

(a)

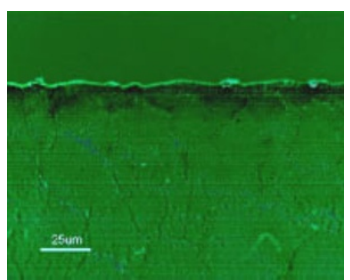

(b)

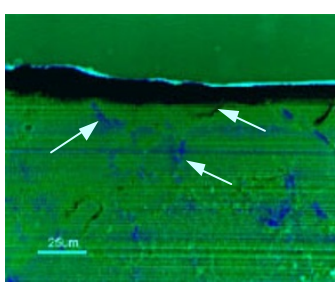

(c)

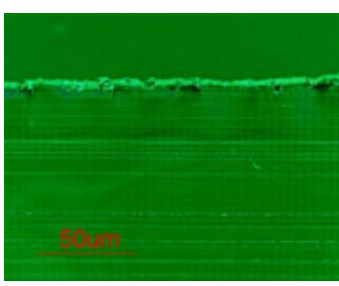

(d)

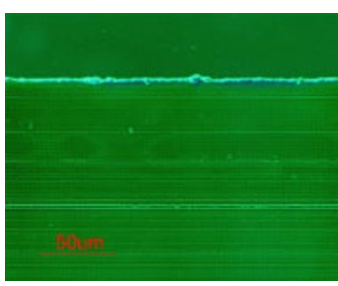

(e)

Figure 7. Cross-section polarization microscopic images for (a) Untreated UHMWPE, (b) DOA-impregnated UHMWPE, (c) DOA-impregnated UHMWPE, (d) Untreated PC and (e) ADE impregnated PC. Here the treatment conditions of time, temperature and pressure for (b) and (e) were $1 \mathrm{~h}$, $373 \mathrm{~K}$ and $20 \mathrm{MPa}$, respectively, whereas for (c), the conditions of $6 \mathrm{~h}, 373 \mathrm{~K}, 20 \mathrm{MPa}$ were applied. Arrows in (c) indicates crystal grain boundary.

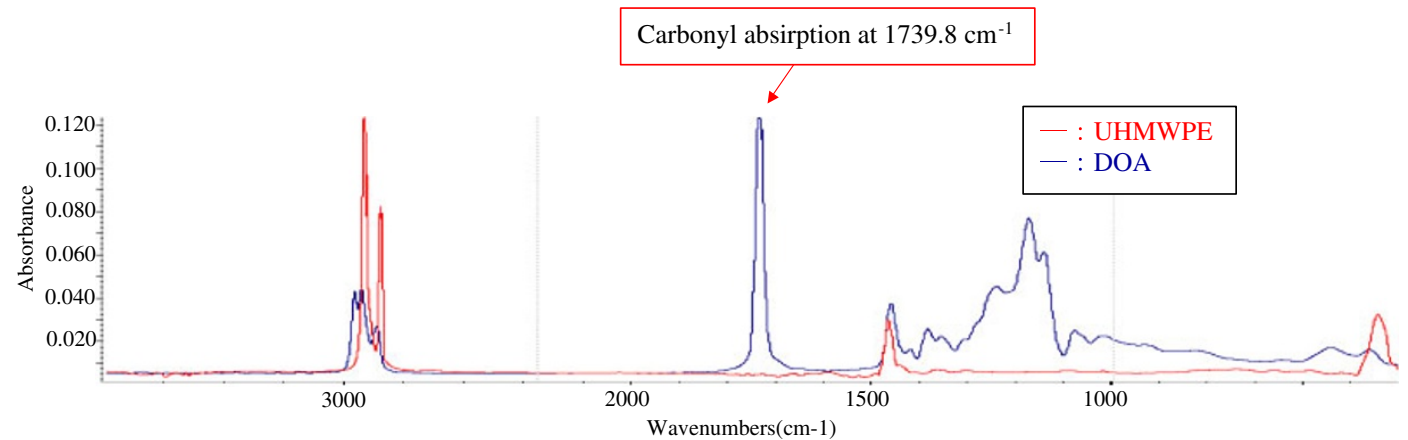

(a)

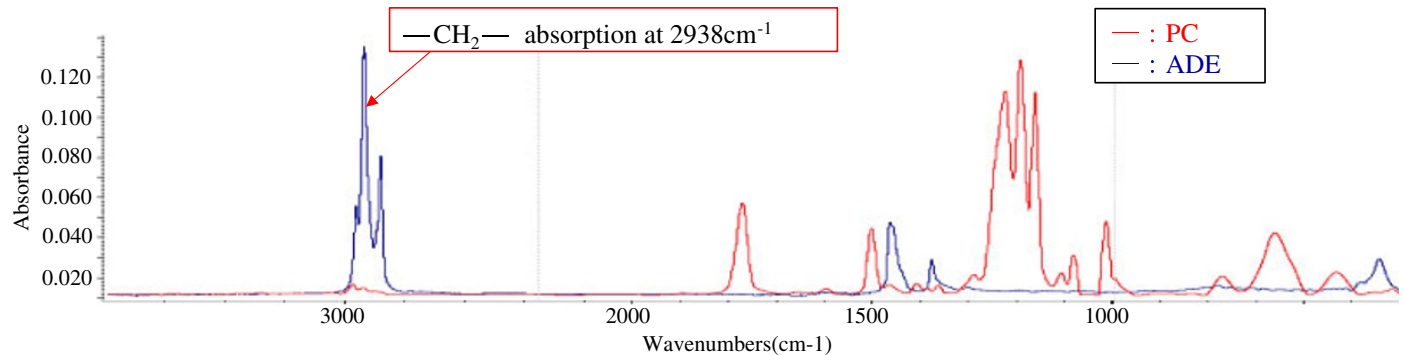

(b)

Figure 8. FT-IR spectra of (a) UHMPE and DOA, and (b) PC and ADE.

polymer in the depth direction, the analysis of thin film specimen by a FT-IR microscope system was carried out.

The overlapped FT-IR spectra of UHMPE and DOA, and PC and $\mathrm{ADE}$ are illustrated in Figure 8. From these data, we defined the absorptions of carbonyl group at $1739.8 \mathrm{~cm}^{-1}$ for UHMWPE/DOA and $\mathrm{CH}_{2}$ (C-H expansion and contraction) at $2938 \mathrm{~cm}^{-1}$ for $\mathrm{PC} / \mathrm{ADE}$ as the characteristic absorptions of DOA and ADE, respectively. Then, using these characteristic absorptions we carried out the analyses of thin film specimens by a FT-IR microscope system. The results of the surface and the vertical cross-section analyses in the thickness are shown in
Figure 9 and Figure 10, respectively.

The following two points are discussed based on the results of surface and vertical cross-section analyses which were carried out to elucidate the dispersion state of lubricating oil impregnated in crystalline polymer.

\section{Difference in Dispersion State of Lubricating Oil between UHMWPE/DOA and PC/ADE}

Figure 10a showing the result of vertical cross-section analysis for UHMWPE/DOA, shows the distribution of DOA in UHMWPE was non-uniform, and the high-concentration 


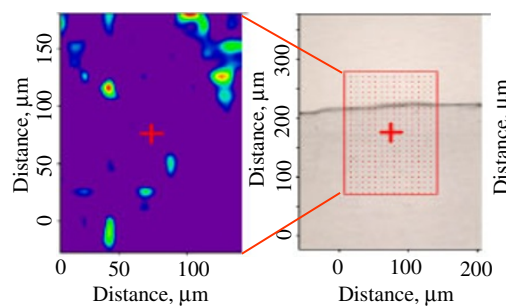

(a)

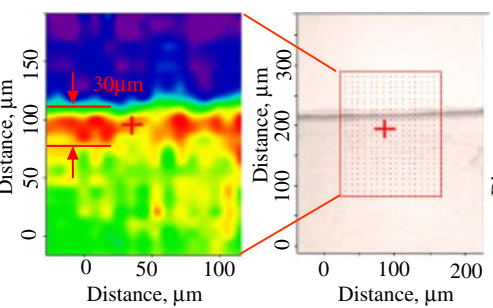

(b)

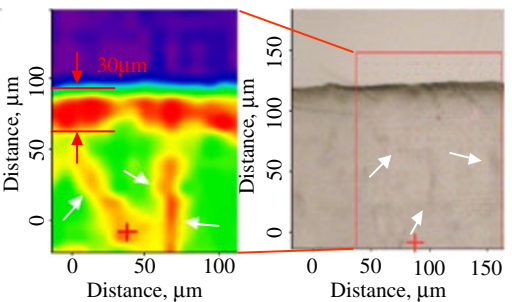

(c)

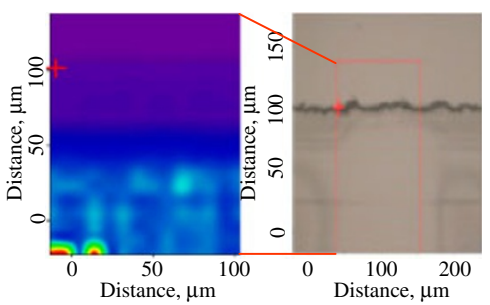

(d)

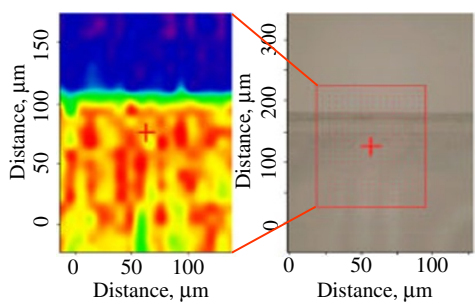

(e)

Figure 9. Optical micrographs and FT-IR mapping images of oil dispersions in (a) Untreated UHMWPE, (b) DOA-impregnated UHMWPE, (c) DOA-impregnated UHMWPE, (d) Untreated PC and (e) ADE-impregnated PC. Here the treatment conditions of time, temperature and pressure for (b) and (e) were $1 \mathrm{~h}$, $373 \mathrm{~K}$ and $20 \mathrm{MPa}$, respectively, whereas for (c), the conditions of $6 \mathrm{~h}, 373 \mathrm{~K}, 20 \mathrm{MPa}$ and the rapid cooling and pressure reduction were applied. Arrows in (c) indicates crystal grain boundary.

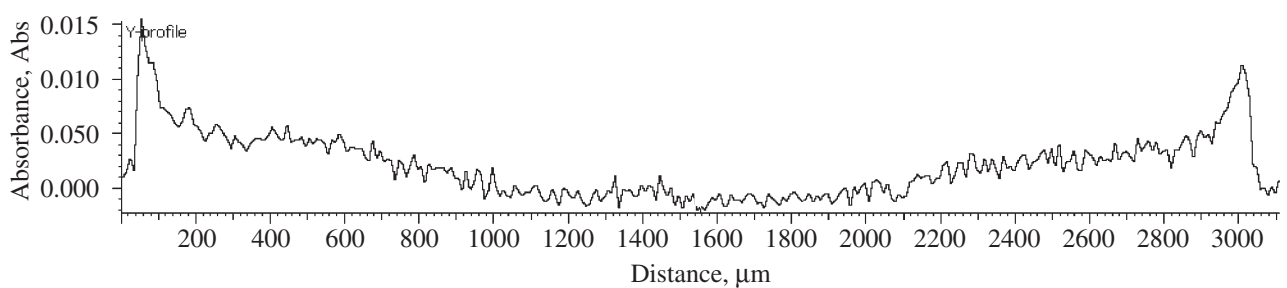

(a)

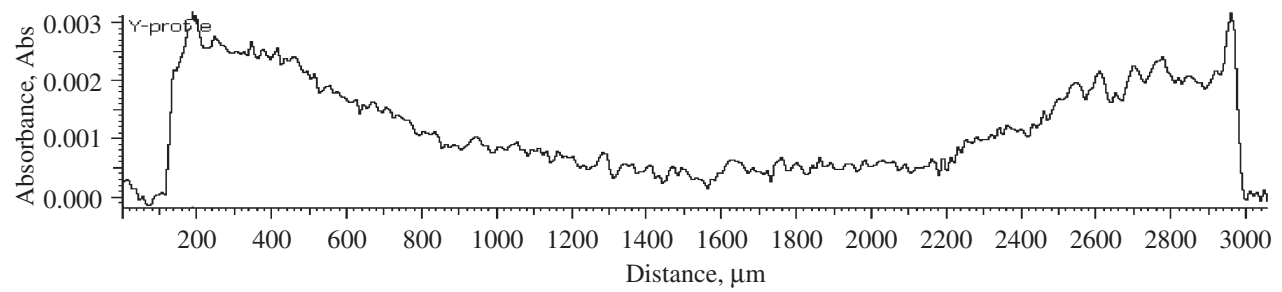

(b)

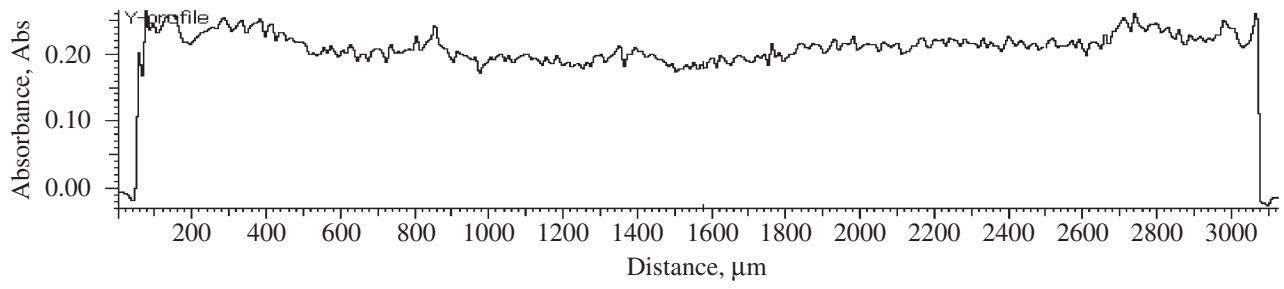

(c)

Figure 10. Results of vertical cross-section analyses in thickness by a FT-IR microscope system for (a) DOA-impregnated UHMWPE, (b) DOA-impregnated UHMWPE and (c) ADE impregnated PC. Here the treatment conditions of time, temperature and pressure for (a) and (c) were $1 \mathrm{~h}, 373 \mathrm{~K}$ and $20 \mathrm{MPa}$, respectively, whereas for (b), the conditions of $6 \mathrm{~h}, 373 \mathrm{~K}, 20 \mathrm{MPa}$ and the rapid cooling and pressure reduction were applied.

layer of DOA having the thickness of $c a .30 \mu \mathrm{m}$ was formed at the vicinity of surface area. On the other hand, the formation of such the high-concentration layer was not recognized in ADEimpregnated PC as shown in Figure 10c, namely, it was revealed that the distribution of ADE was almost uniform from the surface to the core.

Concerning the formation of high-concentration layer of lubricating oil recognized in crystalline polymer, as the oil 
impregnation mechanism, the following would be considered. First, lubricating oil dissolved in supercritical carbon dioxide and supercritical carbon dioxide would be naturally impregnated into the amorphous regions on the top surface. Then, the infused oil and carbon dioxide, which penetrate the intermolecular region in the amorphous phase, would increase the free volume (swelling or plasticizing effect). Due to such the effect, the ordered-structure, i.e., the folded-chain structure in the crystalline regions would be disordered, which would consequently allow the further impregnation of oil and carbon dioxide in the supercritical condition. Such a oil impregnation mechanism can be assumed to the system dealt with in this study. However, Figure 9b and Figure 10a apparently indicate that under our experimental condition, it was until several tens of $\mu \mathrm{m}$ depth below the surface that lubricating oil and carbon dioxide were impregnated in crystalline polymer according to the mechanism described above. That is, from the result in Figure 9, it can be understood that concerning the region below ca. $30 \mu \mathrm{m}$ depth from the surface, the lubricating oil dissolved in supercritical carbon dioxide and supercritical carbon dioxide selectively diffuse into amorphous regions or crystal grain boundary, and would not give rise to the serious destruction of crystal structure in the core of polymer molding.

In addition, little changes in the surface properties were observed after the treatments under this impregnation condition. In the case of UHMWPE/PAO, for instance, the change in surface roughness parameter $\mathrm{Ra}$, which is the arithmetic average of the absolute values, before and after the treatment was just $0.003 \mu \mathrm{m}$.

Thus this result would suggest that our oil impregnation treatment for engineering plastics carried out by utilizing the supercritical carbon dioxide might become a promising technique by which the lubricating surface layer whose thickness would be several tens of $\mu \mathrm{m}$ can be formed, and thereby the tribological characteristics of crystalline plastics would be improved very efficiently.

In case of the non-crystalline polymer such as PC, on the other hand, the lubricating oil can be impregnated uniformly due to the very low crystallinity as shown in Figure 9e and Figure 10c.

\section{Rapid Cooling and Pressure Reduction}

In order to elucidate the influence of cooling process after stopping the supercritical carbon dioxide treatment on the oil impregnation ratio, the oil impregnation experiment with rapid cooling and pressure reduction process was carried out. In this experiment, UHMWPE and DOA were used as samples.

The DOA dispersion state in the depth direction of thin DOA-impregnated UHMWPE specimen treated by the method with rapid cooling in contrast to the ordinary way of applying the gradual cooling is shown in Figure 9c and Figure 10b. As shown in Figure 9c, in case of applying the rapid cooling and pressure reduction, the formation of high-concentration layers were observed at the vicinity of surface area and in the region that would be thought to the grain boundary. Further, a comparison of peak intensities in Figure 10a and in Figure 10b indicates that the impregnation ratio with rapid cooling and pressure reduction was one and a half times higher than that in case of applying the ordinary procedure. This would be attributed to the following presumed reason.

Namely, it can be assumed that in case of applying the gradual cooling and pressure reduction, carbon dioxide with the lubricating oil dissolved was gradually liberated from the polymer containing oil and carbon dioxide because the supercritical condition would be maintained for some period of time after stopping the treatment. On the other hand, when applying the rapid cooling and pressure reduction it can be speculated that the gas-liquid separation of the supercritical fluid mixture of carbon dioxide and the lubricating oil might occur rapidly, and then the gasified carbon dioxide would be liberated from the polymer containing oil and carbon dioxide separately, whereas the liquefied lubricating oil having much higher molecular weight than carbon dioxide would be left in the polymer. That is to say, it would be also considered that Figure $9 c$ and Figure $10 \mathrm{~b}$ reveal the dispersion state of lubricating oil dissolved in carbon dioxide just under the supercritical condition.

On the basis of such considerations, consequently, the result that the larger quantity of oil was impregnated in polymer with rapid cooling and pressure reduction condition would be reasonably explained.

\section{Consideration of Impregnation Mechanism for Crystalline Polymer}

Based on the considerations described in the previous sections, we propose the impregnation mechanism of lubricating oil into crystalline polymer under the condition in this study.

(1) Carbon dioxide dissolves the lubricating oil under the supercritical condition.

(2) The lubricating oil dissolved in supercritical carbon dioxide is diffused into amorphous regions on the top surface together with carbon dioxide in the supercritical condition (Refer to Figure 11a).

(3) The surface layer (several tens of $\mu \mathrm{m}$ depth below the top surface): The lubricating oil dissolved in supercritical carbon dioxide and supercritical carbon dioxide which penetrate the intermolecular space in the amorphous state expand the intermolecular spacing (swelling or plasticizing effect), and due to such the effect, the folded-chain structures in the crystalline regions are unfolded.

(4) The region below several tens of $\mu \mathrm{m}$ depth from the surface: The lubricating oil dissolved in supercritical carbon dioxide and supercritical carbon dioxide selectively diffuse into amorphous regions or crystal grain boundary.

(5) In case of adopting the gradual cooling and pressure reduction; carbon dioxide with the lubricating oil dissolved is gradually liberated from the polymer containing oil and carbon dioxide (Refer to Figure 11b).

(6) In case of adopting the rapid cooling and pressure reduction; the gasified carbon dioxide is liberated from the polymer containing oil and carbon dioxide separately, whereas the 


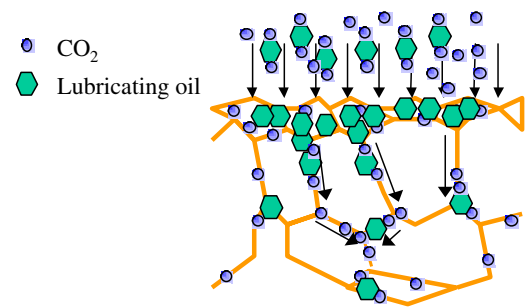

(a)

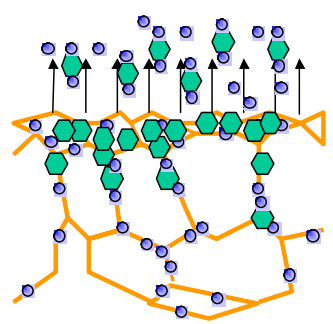

(b)

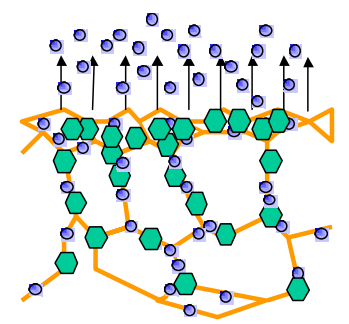

(c)

Figure 11. Presumed oil impregnation mechanism under supercritical carbon dioxide. Here yellow line indicates the crystal grain boundary.

liquefied lubricating oil having much higher molecular weight than carbon dioxide is left in the polymer (Refer to Figure 11c).

\section{CONCLUSION}

The impregnation experiments of lubricating oils into engineering plastics in supercritical carbon dioxide were carried out for the final purpose of establishing a new technique to improve their tribological characteristics. The influence of treatment conditions on the oil impregnation ratio and the oil dispersion state was investigated, and the oil impregnation mechanism under the existence of supercritical carbon dioxide was discussed in this paper.

From the analysis result of oil dispersion state, it was revealed that the lubricating oil was impregnated to the amorphous region in crystalline polymer preferentially. Further, it was visually ascertained the high-concentration layer of lubricating oil having the thickness of about $30 \mu \mathrm{m}$ was formed at the vicinity of the surface area of polymeric materials.

Concerning the oil impregnation mechanism for the crystalline polymer under the condition in this study, the following mechanism was considered. First, the lubricating oil dissolved in supercritical carbon dioxide is infused into amorphous regions on the top surface together with carbon dioxide in the supercritical condition. Then, the infused lubricating oil and carbon dioxide expand the intermolecular space (swelling or plasticizing effect), and due to such the effect, the folded-chain lamellar crystals in the surface layer with the thickness of several tens of $\mu \mathrm{m}$ are unfolded.

The more detail analysis of results of oil impregnation experiments in supercritical carbon dioxide will be done, and the analysis result together with the tribological properties of the oil-impregnated polymer will be reported in the near future.
Received: November 19, 2007

Accepted: April 29, 2008

Published: July 2, 2008

\section{REFERENCES}

1. J. J. Watkins and T. J. McCathy, Chem. Mater., 7, 1991 (1995).

2. A. Kongdee, S. Okubayashi, I. Tabata, and T. Hori, J. Appl. Polym. Sci., 105, 2091 (2007).

3. B. J. Novick, J. M. DeSimone, and R. G. Carbonell, Ind. Eng. Chem. Res., 43, 515 (2004).

4. P. Rajagopalan and T. J. McCarthy, Macromolecules, 31, 4791 (1998).

5. K. Matsuyama and K. Mishima, Nippon Gomu Kyokaishi, 77, 282 (2004).

6. M. Ohsima, Nippon Gomu Kyokaishi, 77, 266 (2004).

7. M. Ohsima, Sen-I Gakkaishi, 60, 429 (2004).

8. S. R. Puniredd, Y. K. Wai, N. Satyanarayama, S. K. Sinha, and M. P. Srinivasan, Langmuir, 23, 8299 (2007).

9. L. H. Sperling, "Introduction to Physical Polymer Science," WileyVCH, Weinheim, 2005.

10. T. Yasuda, Japan Plastics, 51, 125 (2000).

11. T. Yasuda, Japan Plastics, 52, 85 (2001).

12. B. Wunderlich, Polym. Eng. Sci., 18, 431 (1978).

13. E. Maemura, M. Cakmak, and J. L. White, Polym. Eng. Sci., 29, 140 (1989).

14. H. Yamamoto, "Solubility Parameter Basic and Applied and Calculation Method," JOHOKIKO CO., LDT., Tokyo, 2005.

15. K. Arai, Ed., "Latest applied technology of supercritical fluid," NTS Inc., Tokyo, 2004.

16. P. G. Jessop, T. Ikariya, and R. Noyori, Chem. Rev., 99, 475 (1999).

17. S. Siripurapu, J. A. Coughlan, R. J. Spontak, and S. A. Khan, Macromolecules, 37, 9872 (2004).

18. M. Hatanaka and H. Saito, Seikei-Kakou, 14, 89 (2003).

19. M. Ohshima, J. HTSJ, 43, 12 (2004).

20. C. M. Stafford, T. P. Russell, and T. J. McCathy, Macromolecules, 32, 7610 (1999).

21. B.-J. Qu and X. Qu, J. Photopolym. Sci. Technol., 10, 353 (1997).

22. T. T. Ngo, T. J. McCathy, J. S. Brown, M. J. Lazzaroni, K. Counts, C. L. Liotta, and C. A. Eckert, J. Appl. Polym. Sci., 88, 522 (2003). 